\title{
CONFERÊNCIA
}

\section{GESTÃO DA ESCOLA BÁSICA PÚBLICA E BNCC: quais as implicaçōes? 1}

\author{
Josania Lima Portela Carvalhêdo²
}

\section{INTRODUÇÃO}

A aprovação de um documento de caráter normativo para a educação brasileira altera as intencionalidades do sistema educativo básico e, consequentemente, traz implicações para a gestão escolar. Referimo-nos à Base Nacional Comum Curricular (BNCC) (2017) que, em consonância com o Plano Nacional da Educação (PNE) 2014 - 2024 (BRASIL, 2014), amparada pela Lei de Diretrizes da Educação Nacional (LBD) (BRASIL, 1996) e pelas Diretrizes Curriculares Nacionais para a Educação Básica (DCNEB) (BRASIL, 2013), define um conjunto de aprendizagens como básicas, extensiva a todos os estudantes do País, a fim de que seja garantida uma formação integral do ser humano, por meio da oferta de educação de qualidade.

Essa legislação fundamenta-se na Constituição Federal (BRASIL, 1988), que assegura, em seu Artigo 205, a educação como um direito fundamental: "a educação, direito de todos e dever do Estado e da família, será promovida e incentivada com a colaboração da sociedade, visando ao pleno desenvolvimento da pessoa, seu preparo para o exercício da cidadania e sua qualificação para o trabalho" (BRASIL, 1988, p. 123).

\footnotetext{
1 Texto apresentado na Mesa Temática "Gestão e política educacional da escola pública", no II Encontro Regional do Grupo de Estudos e Pesquisas História, Sociedade e Educação no Brasil (HISTEDBR - UFOPA).

2 Doutora em Educação (UFC). Professora do PPGEd/Universidade Federal do Piaú. Orcid iD: https://orcid.org/0000-0002-4288-2756. E-mail: josaniaportela@gmail.com
} 
Para que tal direito seja efetivado, a Carta Magna (BRASIL, 1988) reconhece a necessidade de que sejam estabelecidos conteúdos mínimos para a educação básica, de maneira a assegurar uma formação geral, não deixando de atender às diversidades regionais. Tendo isso em vista, garantir uma formação capaz de responder às exigências de um contexto social cada vez mais complexo, estimulando o desenvolvimento de competências para as necessidades da vida e do trabalho, foi a justificativa para a necessidade de criação da BNCC (BRASIL, 2017).

Após a definição da BNCC, as instituições escolares deverão adequar as suas intencionalidades formativas com base em dez competências, a fim de harmonizar-se com a normativa. Pautadas pelas competências gerais determinadas, no âmbito das escolas, tais instituições precisarão ajustar/alinhar a sua práxis, a começar pela atualização do Projeto Político Pedagógico (PPP), implicando, ainda, a formação continuada de professores, daí porque a gestão escolar deve empreender esforços para essa empreitada.

Para fomentar essa discussão, organizamos 0 presente texto destacando a gestão escolar e o trabalho desenvolvido no contexto da educação básica pelo gestor escolar, evidenciando as principais determinações da BNCC para a educação brasileira, com o propósito de concluir que a normativa traz implicações para a gestão escolar, pois requer a elaboração/reelaboração do Projeto Político Pedagógico, compreendendo as competências propostas na normativa.

\section{GESTOR ESCOLAR: campo de atuação no contexto da educação básica pública}

A gestão escolar é composta por uma equipe de profissionais responsáveis pela condução dos processos administrativos e pedagógicos das instituições de ensino. "Originário do latim gestione, o conceito de gestão refere-se à ação e ao efeito de gerir ou de administrar" (OLIVEIRA; VASQUES-MENEZES, 2018, p. 879). 
No âmbito da gestão escolar pública, o diretor assume o papel de coordenador das atividades gerais da escola em várias áreas e, nesse cenário, avoca um conjunto de responsabilidades a serem partilhadas tanto com os sistemas de ensino ou com a sociedade, como com os diferentes segmentos da instituição, em várias frentes, a exemplo de: matrículas; gestão financeira; transporte escolar; organização da estrutura física e manutenção predial; controle de materiais, mobiliários, equipamentos e registros escolares; alimentação escolar; alimentação das informações educacionais junto aos sistemas de ensino e ao Ministério da Educação (MEC); comunicação com a comunidade interna e externa à instituição; recursos humanos (avaliação de desempenho, férias, faltas, licenças e afastamentos etc.); tecnologias educacionais, entre outras.

Essas frentes de atuação do gestor podem ser agrupadas em seis pilares da gestão, a saber: acadêmico e pedagógico; administrativo; financeiro; de pessoas; da comunicação; de tempo e eficiência dos processos (controle e avaliação) (UNILASALLE, 2019), respaldando-se a gestão escolar na articulação desses suportes para o bom funcionamento da escola.

É válido ressaltar que em uma gestão democrática e participativa, conforme prescrito para as instituições públicas, a partir da Constituição Federal em vigor (BRASIL, 1988), embora o gestor escolar partilhe as responsabilidades com os diferentes segmentos no domínio da escola e fora dela - por exemplo, com coordenadores pedagógicos, professores, sistemas de ensino ou com a própria sociedade - ele participa de todas essas ações desenvolvidas na escola, direta ou indiretamente. Podemos, portanto, compreender a complexidade e a abrangência da ação gestora.

Mas todas as ações da gestão escolar situam-se em função da razão primeira da existência de uma instituição escolar, ou seja, a sua intencionalidade educativa, que abrange o pilar da dimensão pedagógica da função gestora, cumprindo a sua missão social na sociedade brasileira. Dessa forma, embora relevante para a consecução dos fins educacionais, o pilar administrativo da função gestora, em união com os demais, existem em 
função do pedagógico. Essa razão primeira da gestão educacional, para Oliveira e Vasques-Menezes (2018), conduz o ato de planejar, organizar, dirigir e controlar todas as ações e os recursos da instituição escolar para que os objetivos educacionais sejam alcançados.

Assim, de acordo com Libâneo (2007, p. 324), "[...] considerando o caráter intencional de suas ações e interações sociais que estabelecem entre si e com o contexto sociopolítico, nas formas democráticas de tomada de decisões", a ação do gestor escolar, no âmbito do pilar que alude à dimensão pedagógica, deve ter por base O PPP, que sistematiza a intencionalidade das ações a serem desenvolvidas para a garantia da oferta de uma educação integral e de qualidade para a população brasileira, concorde com o previsto na Constituição Federal do Brasil (BRASIL, 1988).

A elaboração ou reelaboração do PPP em cada escola, alinhado com os princípios da BNCC, como prevê a própria resolução que institui e orienta a implantação da BNCC (BRASIL, 2017), deve ser cumprida com a efetiva participação de seus docentes e dos demais membros da comunidade escolar.

Nessa perspectiva, a participação da comunidade escolar configurase como inescusável para a democratização dos processos de tomada de decisão no âmbito escolar, concorrendo para que os participantes assumam compromissos com a sua execução e avaliação. Não obstante, para deliberar sobre o projeto da instituição, faz-se necessário que aos agentes educativos seja oportunizada a apropriação da proposta base por meio da formação continuada.

Isso posto, no contexto atual, avistamos como implicações para a ação gestora escolar, nas quais os gestores deverão concentrar energias no momento presente, a coordenação dos processos de formação continuada com base na BNCC e a reformulação do PPP da escola, aspectos que discutiremos a seguir. 


\subsection{Gestão escolar, formação continuada e BNCC}

Como ressaltamos, se a BNCC "[...] deve nortear os currículos dos sistemas e as redes de ensino das unidades federativas, como também as propostas pedagógicas das escolas públicas e privadas de Educação Infantil, Ensino Fundamental e Ensino Médio de todo o Brasil" (PEREZ, 2018, p. 20), em nível escolar, a gestão deve mobilizar-se visando à adequação de seu projeto à normativa, observando que, de acordo com os documentos, as competências devem, para além de serem apropriadas no contexto escolar, ser vivenciadas nele. Portanto, as competências devem ser trabalhadas no contexto escolar sob uma dimensão prática, e não apenas teórica.

Consequentemente, a dimensão prática da ação pedagógica deve permear os processos de formação. A começar pela formação dos professores, como afirmam Oliveira e Carvalhêdo (2019), porquanto a prática deve assumir uma posição de centralidade, pois se afastar dela pode motivar uma formação restrita apenas à base teórica, sem significado para o contexto escolar. Portanto, a formação deve, além de possibilitar a apropriação dos princípios e conteúdos da BNCC, pela equipe gestora e pelos professores da escola, favorecer a elaboração ou reelaboração do PPP pelos professores no âmbito escolar, e enfatizar práticas relacionadas às dez competências a serem desenvolvidas no ensino básico.

Nessa acepção, Perez (2018) aduz que a BNCC passa a ser referência nacional obrigatória para as políticas de formação de professores, ou seja, a formação desses profissionais deve estar alinhada aos princípios que norteiam o susodito documento. Dessa forma, a formação continuada a ser desenvolvida no contexto da escola pública, para subsidiar a reformulação do PPP, deve contemplar a necessidade de apropriação da BNCC na mediação da prática pedagógica, com base nas competências gerais a serem desenvolvidas no âmbito escolar, coadunando a orientação do documento.

O que a BNCC propõe é que as competências a serem desenvolvidas não sejam restritas aos aprendizes, mas que todos os envolvidos possam 
vivenciá-las no dia a dia da instituição de ensino. Por exemplo, a competência da empatia, do diálogo, da resolução de conflitos e da cooperação devem ser mobilizadas diariamente nas interações sociais que acontecem no espaço intra e extraescolar.

Mas como desenvolver essas competências? Essa decisão é da própria escola, consciente de que essa aprendizagem não deve ser restrita ao espaço da sala de aula, uma vez que toda a escola deve se envolver em sua consecução. Quando a escola, de forma coletiva, dialoga com respeito às diversidades de pontos de vista e encontra uma solução para os seus problemas, exercita outra competência apontada na BNCC, qual seja a questão da autonomia, comprometendo-se subjetivamente com as decisões propostas.

Portanto, "agir pessoal e coletivamente com autonomia, responsabilidade, flexibilidade, resiliência e determinação, tomando decisões com base em princípios éticos, democráticos, inclusivos, sustentáveis e solidários" (PEREZ, 2018, p. 24), é uma das competências que deve ser desenvolvida no horizonte da escola básica, levando ao alcance de outras competências.

Os processos formativos de professores devem considerar, corroborando Garcia (1999, p. 26), a escola como contexto da ação; o currículo como espaço de intervenção; e o ensino como tarefa desse profissional, sendo a formação compreendida como processos em que tais profissionais, seja individualmente ou em equipe, implicam "[...] experiências de aprendizagem através das quais adquirem ou melhoram os seus conhecimentos, competências e disposições, e que lhes permite intervir profissionalmente no desenvolvimento do seu ensino, do currículo e da escola [...]", sempre tendo como objetivo o aperfeiçoamento da qualidade da educação ofertada à sociedade.

A formação continuada, para os que já estão inseridos no contexto educativo, de acordo com Garcia (1999), deve manter alguns princípios, quais sejam: continuidade; integração aos processos de mudança; inovação e desenvolvimento curricular; deve estar relacionada ao 
desenvolvimento organizacional da escola; promover a integração entre conteúdos e processos pedagógicos; estimular a integração entre teoria e prática; estabelecer correspondência quanto à dimensão política entre os processos formativos e a educação a ser desenvolvida no âmbito escolar; e, por último, o da individualização, visto que os indivíduos não são homogêneos e cada pessoa possui capacidades e potencialidades, em conformidade com as suas características, sendo oportunizado espaços para troca de ideias e experiências para questionarem as suas próprias concepções e práticas, desenvolvendo-se na coletividade.

Ademais, além de esses processos formativos serem adequados às necessidades dos professores e condições da formação (momento, se é voluntária, obrigatória etc.), podem ser realizados a partir de vários modelos, tanto no próprio ambiente escolar como fora dele. À vista disso, Garcia (1999) explica que a formação, no âmbito do desenvolvimento profissional, pode ocorrer de múltiplas formas, e aponta cinco paradigmas: autônoma; a partir de espaços reflexivos com os próprios pares, com o apoio e a supervisão pedagógica (reflexão, apoio profissional e supervisão); baseado no desenvolvimento curricular da escola; em cursos de formação na escola ou fora dela; e a partir da investigação da própria prática.

O importante, como gestor escolar, é definir os processos formativos junto ao coletivo da escola, a fim de que se efetive "[...] um processo de aprendizagem mediante o qual alguém (professores, diretores), deve aprender algo (conhecimentos, competências, disposições, atitudes), num contexto concreto (escola) [...]" (GARCIA, 1999, p. 193).

\subsection{A ação gestora na elaboração/reformulação do PPP}

Como apontado anteriormente, a atuação do gestor escolar no âmbito do pilar administrativo tem como fulcro a coordenação da elaboração coletiva da ação pedagógica da escola, incrementando uma gestão participativa e democrática, em consonância com o estabelecido constitucionalmente (BRASIL, 1988). 
A dimensão pedagógica da gestão escolar é desenvolvida com base na liderança exercida pelo gestor, a começar pela construção coletiva do PPP ou sua reformulação para adequação a BNCC, exigência do contexto atual (BRASIL, 2017).

Logo, a cultura organizacional da escola deve favorecer tanto a ação de formação de professores quanto de elaboração ou reformulação do PPC, primando pelos princípios democráticos. Como competência assumida na dimensão pedagógica, cabe ao gestor escolar coordenar, em conjunto com os outros componentes da equipe gestora (vice-diretor e coordenador pedagógico) e em colaboração com a comunidade escolar, as ações relativas à organização e coordenação das atividades de planejamento educacional na elaboração do Projeto Político Pedagógico, além do acompanhamento da sua execução e avaliação das ações desenvolvidas periodicamente, sempre observando as determinações do sistema de ensino ao qual se vincula (Estadual/Municipal).

De acordo com a LDB (BRASIL, 1996), no Artigo 12, O PPP ou a Proposta Político Pedagógica da escola é um instrumento orientador e, em conciliação com as normativas, toda instituição de ensino tem a responsabilidade de elaborar, executar e avaliar, e estabelece as intenções e estratégias para o processo pedagógico a ser desenvolvido na escola.

Para Franco (2016, p. 247), os PPP são "[...] organizadores da esfera pedagógica da escola [...]", convergindo todas as práticas educativas, compreendidas como "[...] práticas que ocorrem para a concretização de processos educacionais, para a sua efetivação. Então, o PPP direciona as ações educativas produzidas no contexto escolar, fundamentadas em uma intencionalidade, revelando a dimensão política da escola, pois as práticas educativas a serem desenvolvidas no espaço escolar são resultantes de decisões conscientes envolvendo a totalidade do corpo escolar.

Voltando um pouco e vislumbrando a história da educação no Brasil, concebemos que há alguns anos, o gestor escolar centralizava a tomada de decisão, pouco partilhando com a comunidade interna e externa da escola as decisões a serem tomadas. Todavia, com as transformações ocorridas a

Revista Exitus, Santarém/PA, Vol. 10, p. 01-12, e020002, 2020. 
partir da redemocratização da sociedade brasileira na segunda metade da década de 1980, e a consequente garantia constitucional de espaços democráticos e participativos, preconizada pela Constituição Federal (BRASIL, 1988) e reforçada pela LDB - Lei n 9.394/96 (BRASIL, 1996), atinamos para a exigência de que esse documento que norteia as ações escolares deva ser fruto de produção coletiva, pressupondo sempre uma ação pública que traz impressas as intencionalidades educativas da escola.

Como adendo, salientamos que na relação entre os entes constitutivos do sistema educacional brasileiro, nas esferas federal, estadual e municipal, inclui-se o princípio da colaboração, igualmente previsto na legislação brasileira. Por isso, chamamos a atenção para o fato de que na proposta reflexiva deste texto, tratamos a BNCC no âmbito da escola, mas não anulamos, com esse recorte, o fato de que todo o processo de elaboração e a própria implementação da BNCC está sendo realizada com a colaboração entre os entes federados, de forma a assegurar que as orientações propostas no documento atendam às diferentes realidades das escolas brasileiras. Portanto, até chegar à escola, a parceria entre União, Estados e Municípios constitui um meritório dinamizador para a sua efetivação no âmbito das escolas.

Após esse esclarecimento, retomamos o espaço escolar para dizer que, como resultado do processo de redemocratização do País, as escolas passaram contar com maior autonomia administrativa, pedagógica e financeira. Tal soberania trouxe consigo o aumento da complexidade das tarefas da gestão, com implicações na forma de organização políticopedagógica para o avanço teórico-prático da educação e da própria gestão, sendo o gestor responsável pela mobilização dos diversos segmentos para o alcance de fins educacionais, conduzindo a elaboração ou reformulação do PPC proposta a partir da aprovação da BNCC.

Na acepção de Paro (2001), a condição de responsável último pela escola e de preposto do Estado, no que tange ao cumprimento da lei e da ordem na instituição escolar, agregado à condição de liderança legitimada 
democraticamente pelo voto da comunidade escolar, exige do gestor maior capacidade de mobilização e representatividade.

Para pensar uma nova proposta política pedagógica para a escola, a partir da atual normativa (BNCC), deve-se abranger os processos de: construção do conhecimento; desenvolvimento do pensamento científico, crítico e criativo e da cultura, bem como dos processos comunicativos, com o emprego de diferentes linguagens; compreensão e uso das tecnologias de informação; relações de trabalho e escolhas alinhadas ao exercício da cidadania e ao projeto de vida; desenvolvimento da capacidade de argumentação, com base em fatos, dados e informações confiáveis; autoconhecimento e do autocuidado; diálogo e da resolução de conflitos sem preconceitos de qualquer natureza; e autonomia, tomando decisões de acordo com princípios éticos (PEREZ, 2018).

Tendo por base as competências que devem ser desenvolvidas, visando ao cumprimento do papel da escola, qual seja de "[...] gerar condições para que todos aprendam [...] (PEREZ, 2018, p. 78), o gestor conduz o processo de elaboração e reformulação tendo como ponto de partida a análise da realidade da escola pelo seu coletivo, a fim de avaliar as práticas que vêm sendo desenvolvidas na escola, de forma crítica, com vistas a selecionar aquelas que já colaboram para desenvolver as competências gerais e assimilar o que terá de ser alterado, tanto em termos de cultura escolar como de práticas educativas.

Parte, pois, do marco situacional, que é a expressão da compreensão do grupo que planeja, designando o seu olhar sobre uma realidade mais ampla, seus traços marcantes, seus avanços e suas fragilidades para propor as transformações.

\section{CONSIDERAÇÕES FINAIS}

As determinações da BNCC trazem implicações para a gestão escolar, pois a equipe gestora deve assumir a responsabilidade pela condução do processo de elaboração/reelaboração do PPP, que parte da formação continuada, seja em serviço ou externa à escola, assumindo, portanto, 
modelos diferentes, mas tendo a prática pedagógica desenvolvida no contexto escolar como centralidade nos processos formativos.

Nos sistemas de ensino onde aconteceu o cumprimento da Meta 19 (dezenove) do PNE, a partir de 2016, houve a efetivação da gestão democrática, garantindo legitimidade aos gestores que foram eleitos democraticamente, assumindo, com a sua eleição, a condição reconhecida de liderança local, respaldada pela comunidade escolar. Por cúmulo, o fortalecimento da gestão democrática viabiliza o desenvolvimento da capacidade de mobilização do gestor escolar, da qual depende a implantação da política pública para o alcance da qualidade de ensino, pois consoante Lück (2012, p. 48), "a qualidade do ensino depende de que as pessoas afetadas por decisões institucionais exerçam o direito de participar desse processo de decisões, assim como tenham o dever de agir para implementá-las".

Portanto, a BNCC carece de pessoas comprometidas para a sua operacionalização, já que a normativa por si só não produz mudanças. Nessa constatação, entendemos que o gestor escolar assume responsabilidades políticas com a proposta a ser implementada, as quais se revelam a começar pela sensibilização da comunidade escolar, de forma que Ihes permita compreender a relevância e a amplitude da base a ser operacionalizada e a repercussão de cada decisão tomada pela coletividade para a qualidade de seu processo educacional, no sentido da autonomia e do seu desenvolvimento.

Antes de concluir, é oportuno afirmar que, em termos de gestão, só havendo credibilidade junto aos pares é possível mobilizar a comunidade para o alcance de um objetivo comum. Para tanto, deve existir coerência entre as ideias professadas e a prática efetivada, sendo que na escola, a ação gestora, dentre os pilares de atuação, deve centrar os esforços na dimensão pedagógica.

Portanto, nesse momento educacional, a política pública regulatória dos processos educacionais na educação básica (BNCC) deve ser implementada, instigando ao gestor escolar a concentrar energias, 
concentrando o foco de ação no pilar pedagógico, pela importância central que este assume para o cumprimento da função social da escola.

\section{REFERÊNCIAS}

BRASIL. Constituição da República Federativa do Brasil. Brasília, DF: Senado, 1988.

BRASIL. Lei n 9.394/96. Lei de Diretrizes e Bases da Educação Nacional. Brasília: MEC, 1996.

BRASIL. Diretrizes Curriculares Nacionais para a Educação Básica. Brasília, DF: MEC; SEB, 2013.

BRASIL. Lei n 13.005, de 25 de junho de 2014. Aprova o Plano Nacional de Educação - PNE e dá outras providências. Diário Oficial da União, Brasília, 26 jun. 2014. Disponível em: http://www.planalto.gov.br/ccivil_03/_ato20112014/2014/lei/l13005.htm. Acesso em: 1 nov. 2019.

BRASIL. Portaria n 1.570/2017 - CNE. Aprova a Base Nacional Comum Curricular - BNCC Ensino Médio. Diário Oficial da União n² 244, de 21/12/2017, Seção 1, p. 146.

GARCIA, C. M. Formação de professores: para uma mudança educativa. Porto: Porto, 1999.

LIBÂNEO, J. C. A organização e a gestão da escola: teoria e prática. Goiânia: Alternativa, 2007.

LÜCK, H. A gestão participativa na escola. Petrópolis, RJ: Vozes, 2012.

OLIVEIRA, I. C.; VASQUES-MENEZES, I. Revisão de literatura: o conceito de gestão escolar. Cadernos de Pesquisa, v.48, n.169, p.876-900, jul./set. 2018.

OLIVEIRA, M. S. B.; CARVALHÊDO, J. L. P. Formação e profissionalização docente: refletindo sobre a centralidade da prática pedagógica. In: MENDES SOBRINHO, J. A. de C. (org.). Formação docente: desafios e possibilidades. São Paulo: Garcia Edizioni, 2019.

PEREZ, T. BNCC: a Base Nacional Comum Curricular na prática da gestão escolar e Pedagógica. São Paulo: Moderna, 2018.

UNILASALLE. O que é gestão escolar? Rio de Janeiro: Unilasalle, 2019.

Recebido em: 19 de setembro de 2019 Aprovado em: 11 de novembro de 2019 